\title{
V. Autoras y Autores
}

\section{Nieves Montesinos Sánchez}

Doctora en Derecho. Profesora Titular de Derecho Eclesiástico del Estado. Universidad de Alicante. Directora del Centro de Estudios sobre la Mujer de la Universidad de Alicante. Cofundadora e Integrante del Seminario Universitario sobre los Derechos de las Mujeres. Cofundadora e integrante de la Red Feminista de Derecho Constitucional. Integrante de AUDEM.

\section{Mar Esquembre}

Profesora Titular de Derecho Constitucional. Vicepresidenta de la Red Feminista de Derecho Constitucional, de la que fue cofundadora. Sus líneas de investigación se enmarcan especialmente en torno a la cuestión de la ciudadanía y los sujetos constitucionales, así como en la metodología de investigación y enseñanza del derecho constitucional con la incorporación de las teorías feministas.

\section{Mónica Moreno Seco}

Profesora Titular de Historia Contemporánea de la Universidad de Alicante, integrante de la Junta Directiva de la Asociación Española de Investigación en Historia de las Mujeres y directora de la revista Pasado y Memoria. Ha investigado en la historia de las mujeres y de género en la España del siglo XX.

\section{Carmen Mañas Viejo}

Profesora Titular de la Universidad de Alicante, pertenece al Departamento de Psicología Evolutiva y Didáctica. Coordinadora del área de publicaciones del Centro de Estudios sobre la Mujer de la Universidad de Alicante y coordinadora de la Red-COEDUCA desde el 2007. Desarrolla su docencia en la Facultad de Educación y en la Facultad de Derecho.

\section{Mariló Berenguer Ros}

Técnica Especialista en Imagen y Sonido. Trabajando desde 1995 en la Universidad de Alicante como Operadora de Cámara y realizando labores de Producción.

\section{Mariló López Tébar}

Ingeniera Técnica Informática de Gestión. Consultora, analista y programadora de aplicaciones Web. Desarrolladora de ERP Microsoft Busines Solution AXAPTA y MCP de Microsoft Dynamics CRM 3.0. 


\section{Pilar Ballarín Domingo}

Es Catedrática de Teoría e Historia de la Educación de la Universidad de Granada y miembro del Instituto de Estudios de la Mujer de esa Universidad. Su línea principal de investigación, que ha dado lugar a numerosas publicaciones, es la historia de la educación de las mujeres, con especial atención al periodo contemporáneo en España, en el que se ha ocupado de distintos temas, desde los orígenes de la escolarización femenina y su desarrollo y las maestras como constructoras de conocimiento educativo, a los Estudios de las Mujeres como compromiso colectivo del feminismo académico contemporáneo con la transformación de los conocimientos.

\section{Ma José Tacoronte Domínguez}

Licenciada en filosofía por la Universidad de La Laguna. Master oficial de filosofía, cultura y sociedad, y Experto de género y políticas de igualdad. Su área de investigación se centra en la filosofía de la ciencia, concretamente en las epistemologías feministas y en los estudios sociales de ciencia y género. Becaria de investigación FPI en el Depto de Historia y Filosofía de la ciencia, la Educación y el Lenguaje de la Facultad de Filosofía de la Universidad de La Laguna. Becaria del Instituto Universitario de Estudios de las Mujeres, IUEM, e investigadora del Proyecto de Investigación Epistemología, política e institucionalización en el desarrollo científico: La ciencia española de la república a la dictadura. № Ref. FFI2009-09483/FISO.

\section{Teresa Piñero-Otero}

Doctora en Comunicación por la Universidade de Vigo. Ha orientado su investigación a los estudios de género, tanto desde la perspectiva de la Comunicación como de la Ciencia y la Tecnología. En la actualidad es docente de la Facultad de Ciencias de la Comunicación de la Universidade da Coruña.

\section{Carmen Costa Sánchez}

Doctora en Comunicación por la Universidade de Santiago de Compostela. Actualmente es profesora de Comunicación Corporativa e Industrias Culturales en la Facultade de Ciencias de la Comunicación de la Universidade da Coruña. Entre sus líneas de investigación destacan los estudios sobre las mujeres en los medios de comunicación.

\section{Marta Martín Llaguno}

Catedrática de Comunicación Audiovisual y Publicidad en la Universidad de Alicante, es doctora en Comunicación Pública por la Universidad de Navarra. Desde que realizó su tesis doctoral sobre el tratamiento del SIDA a través de la prensa, ha investigado a partir de la dirección de proyectos de I+D la construcción social de distintos problemas sociales (violencia 
de género, trastornos de alimentación, enfermedades artificiales, riesgos alimentarios, conflicto familiar y laboral...) en los medios, las agendas parlamentarias y la opinión pública.

\section{Consuelo León Llorente}

Profesora en la Universitat Internacional de Catalunya, escritora, coach. Ha sido subdirectora de la agencia Ecopress e investigadora del IESE en Barcelona.

\section{Cristina Guirao Mirón}

Es Catedrática de EESS. Profesora asociada en las Universidades de Alicante (2003-2005) y Murcia (2005-2011). Contratada Doctora en la Universidad de Murcia. Tesis doctoral (2010): La construcción social del problema de la conciliación vida familiar y laboral en España. 1999-2009. Dirigida por Dr. Doña Marta Martín Llaguno.

\section{Ana Dolores Verdú Delgado}

Licenciada en Antropología Social y Cultural, y Doctora en Estudios e Investigación sobre las Mujeres, Feministas y de Género, por la Universidad Miguel Hernández de Elche. Investigadora y docente colaboradora del Centro de Investigación de Estudios de Género y de las Aulas Universitarias de la Experiencia de la misma universidad.

\section{Beatriz Alvarado}

Doctora en Estudios Sociales y Educación Global. Docente universitaria e investigadora en Perú y en los Estados Unidos. Sus líneas de estudio e interés se enfocan en temas de género, educación y literacidad. Es directora ejecutiva de Killari, una organización sin fines de lucro que busca empoderar a la joven rural andina a través de la educación formal. Entre sus publicaciones destacan estudios de índole cualitativa tales como "Pero no te dejan ser": Gender Dynamics and Leadership in Southern Peru, International Journal of Humanities, 1(2), 149170; Cambiando los roles de las mujeres hispanas/Changing roles of Hispanic women. Revista Venezolana de Estudios de la Mujer, Universidad Central de Venezuela, 38, Vol.17; Gender dynamics in the classroom: Guidelines for an inclusive education - Dinámicas de género en el aula: Pautas para la inclusión en el ámbito educativo. Educación Sin Fronteras (España) - El Taller, Asociación de Promoción y Desarrollo: Perú. Biblioteca Nacional del Peru: 201006638.

\section{Luz Ma Cordero Beas}

Es Maestra de educación infantil, en activo en el CEIP Las Gaviotas, La Antilla, Lepe. Máster en género, identidad y ciudadanía. Responsable del plan de igualdad del CEIP Las Gaviotas desde 2008. 


\section{M. Àngels Francés Díez}

Doctora en Filología Catalana y licenciada en Filología Inglesa. Sus líneas de investigación se centran en la crítica literaria desde una perspectiva de género, la literatura autobiográfica y la literatura comparada. Entre sus publicaciones destacan los monográficos Literatura $i$ feminisme: L'hora violeta, de Montserrat Roig (Tarragona, Arola, 2010) y Montserrat Roig: feminisme, memòria i testimoni (Barcelona, Publicacions de l'Abadia de Montserrat, 2012).

\section{María Ibarí Ortega}

Maestra en Estudios de Asia y África, Especialidad Japón, por El Colegio de México y Maestra en Historia del Arte por el Instituto de Investigaciones Estéticas, UNAM. Sus investigaciones se enfocan en la construcción de género en la cultura visual del periodo Meiji (1868-1912) y el folklore sexual en Japón. De manera paralela, aborda el tema de las representaciones culturales en los museos y en la producción del patrimonio en el contexto asiático. Ha presentado ponencias en seminarios y coloquios internacionales en la Universidad de Michigan, Ann Arbor, EUA y la Universidad de Hitotsubashi, Japón, en 2010, así como en la Conferencia Anual de la Association for Asian Studies, AAS, en Hawaii, en el 2011. He realizado estancias de investigación en Japón y Hawaii. Actualmente es investigadora de la colección de estampa japonesa y curadora asociada en el Museo de Arte Carrillo Gil, en la Ciudad de México.

\section{María Gómez y Patiño}

Doctora UCM (1996). PDI desde 1991 en distintas universidades. Actualmente: Universidad de Zaragoza. Ha publicado varios libros: Propaganda Poética en Miguel Hernández (1999), Calderón: una lectura desde el siglo XXI (2000), Paz: Femenino, singular (2005), Las Huellas de la violencia invisible (2005), Escapistas de la realidad. Los intangibles del turismo (2012) y traducido: El proceso de Opinión Pública (2000). Publica y participa en foros (español e inglés). Es DIRCOM (socio-docente) y miembro del Equipo de Investigación en Comunicación e Información Digital (GICID). Ha sido profesora invitada en diferentes universidades europeas; publica regularmente en journals académicos. 